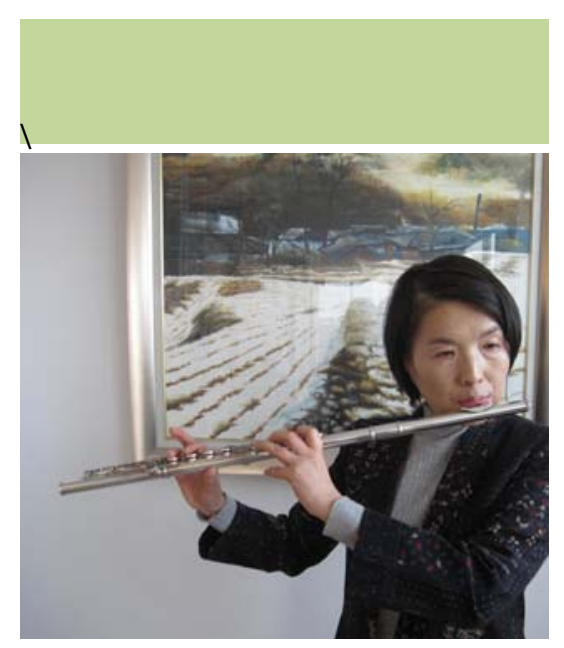

Selected Publications

HS Kim \& HS Kim (2015). The Effect of Musical Instrument Performance on Emotional Intelligence, Anxiety, and Aggression in Korean Elementary School Children. Journal of Research in Music Education (in progress)

HS Kim \& HS Kim (2013). Depression in Non-Korean Women Residing in South Korea Following Marriage to Korean Men. Archives of Psychiatric Nursing, 27, 148155.

HS Kim, HS Kim, \& J. SamuelsDennis (2012).The Influence of Psychosomatic Symptoms, Physical and Sexual Abuse, and Coping Strategies on Delinquent Behavior among Korean Adolescents. Archives of Psychiatric Nursing, 26, 155-164.

KS Lim \& HS Kim (2012). Effect of Life respect Programs for the Elderly on Depression, Suicidal Ideation, and Psychological WellBeing of the Elderly. Journal of Welfare for the Aged, 55, 201-222.

HS Kim (2011). Impacts of Social Support and Life Satisfaction on Depression among International Marriage Migrant Women in Daegu and Kyungpook Area. Journal of Korean Academy of Mental Health Nursing, 20(2), 188198.
INYI Featured Member

\section{Meet Hyun-Sil Kim, PhD}

Hyun-Sil Kim was born in Seoul, South Korea. She graduated from Hanyang University (major in Nursing) and earned a Doctoral degree from Ewha Womans University in Seoul. Her doctoral thesis developed "Structural Equation Model of Delinquent Behaviour influenced by Media Violence" in Korea. She was also a post-doctoral fellow in the Faculty of Nursing, University of Toronto under the supervision of Dr. Nazilla Khanlou (2002-2003).

She is currently a professor in the Department of Nursing at the Daegu Haany University located in Daegu, South Korea. Her research objectives are juvenile delinquency, substance abuse, influence of media violence on delinquent behaviour, family dynamic environment, personality, school violence. She was the principal investigator of a "Development of sublimation program for Korean adolescent's aggression" (funded from Korea Research \& Engineering Foundation at 2001) and "Gender differences in delinquent behaviour among Korean Adolescents" (funded by Korea Research Foundation at 2000). From 2004 to 2006, she wrote the article on value conflict originated in the cultural difference between traditional Korean Confucian culture and western culture among Korean adolescents in Canada. Dr. Kim also participated the research project entitled "Immigrant youth and cultural identity in a global context" (principal investigator: Dr. Nazilla Khanlou, funded by Social Sciences and Humanities Research Council of
Canada from 2003 to 2005) as member of the international advisory panel. In 2007, she published the books entitled 'Adolescent Behaviour Research Advances' and 'Adolescent Behaviour Research Studies', which focused on etiological factors and cultural differences of juvenile delinquency and youth crime, (Nova Publishers, N.Y, U. S.). She is also involved in policy making and development of social integration program for the international marriage migrant women living in South Korea.

For her contribution to this research area, she received numerous awards including the International Health Professional Award of the Year 2007 from the International Biographical Center, UK, and was featured in Who's Who in the World from Marquis Who's Who Publication Board and the Great Minds of the 21st Century from the American Biographical Institute.

From March to August, 2010, she served at School of Nursing, York University as an adjunct professor and visiting scholar. Since 2010, she has expanded her research focus to exam the effects of art-based intervention on emotional problems among immigrant women, children, or the elderly with a language barrier. For performing art-based intervention, she began to study music intervention using a musical instrument performance from 2011 and is currently pursuing a Bachelor's degree in woodwind, musicology (majoring in the flute). Currently, she is involved in a study that examines the effects musical instrument performance on emotional intelligence, anxiety, and aggression in Korean elementary school children as a principal investigator.

Contact: hskim@dhu.ac.kr 